Editorial Manager(tm) for International Journal of Legal Medicine Manuscript Draft

Manuscript Number: IJLM-D-11-00028R1

Title: A COMPARISON OF THREE ESTABLISHED AGE ESTIMATION METHODS ON AN ADULT SPANISH SAMPLE.

Article Type: Original Article

Corresponding Author: Carme Rissech, Ph.D

Corresponding Author's Institution: University of Barcelona

First Author: Carme Rissech, Ph.D

Order of Authors: Carme Rissech, Ph.D;Jeremy Wilson, Ph.D;Allysha Powanda Winburn, Master;Daniel Turbón, Ph.D;Dawnie Steadman, Ph.D

Abstract: Most current methods for adult skeletal age-at-death estimation are based on American samples comprising individuals of European and African ancestry. Our limited understanding of population variability hampers our efforts to apply these techniques to various skeletal populations around the world, especially in global forensic contexts. Further, documented skeletal samples are rare, limiting our ability to test our techniques. The objective of this paper is to test three pelvic macroscopic methods (1-Suchey-Brooks; 2- Lovejoy; 3- Buckberry and Chamberlain) on a documented modern Spanish sample. These methods were selected because they are popular among Spanish anthropologists and because they never have been tested in a Spanish sample. The study sample consists of 80 individuals ( $55 \hat{\sigma}$ and 25 \&) of known sex and age from the Valladolid collection. Results indicate that in all three methods, levels of bias and inaccuracy increase with age. The Lovejoy method performs poorly (27\%) compared with Suchey-Brooks (71\%) and Buckberry and Chamberlain (86\%). However, the levels of correlation between phases and chronological ages are low and comparable in the three methods $(<0.395)$. The apparent accuracy of the Suchey-Brooks and Buckberry and Chamberlain methods is largely based on the broad width of the methods' estimated intervals. This study suggests that before systematic application of these three methodologies in Spanish populations, further statistical modeling and research into the co-variance of chronological age with morphological change is necessary. Future methods should be developed specific to various world populations, and should allow for both precision and flexibility in age estimation.

Response to Reviewers: See attachment 


\section{A COMPARISON OF THREE ESTABLISHED AGE ESTIMATION METHODS ON AN ADULT SPANISH SAMPLE.}

Rissech Carme ${ }^{1}$; Wilson Jeremy ${ }^{2}$; Winburn Allysha $\mathrm{P}^{3}$; Turbón Daniel $^{1}$ and Steadman Dawnie ${ }^{4}$

1- Unit of Anthropology. Dept of Animal Biology. University of Barcelona. Spain

2- Department of Anthropology. Indiana University-Purdue University, Indianapolis (IUPUI). Indianapolis, IN. USA

3- Department of Anthropology. University of Florida (UF). Gainesville, FL. USA.

4- Department of Anthropology. Binghamton University (SUNY). Binghamton, NY. USA.

\section{CORRESPONDING AUTHOR}

Carme Rissech

Unitat Antropologia

Departament de Biologia Animal

Facultat de Biologia

Av. Diagonal, 645

08028 Barcelona

Telf: (34) 934021460 ext. 213

Fax: (34) 934035740

carme.rissech@ub.edu

KEYWORDS: aging, auricular surface, pubic symphysis, forensic science, adult age. 


\section{ABSTRACT}

Most current methods for adult skeletal age-at-death estimation are based on American samples comprising individuals of European and African ancestry. Our limited understanding of population variability hampers our efforts to apply these techniques to various skeletal populations around the world, especially in global forensic contexts. Further, documented skeletal samples are rare, limiting our ability to test our techniques. The objective of this paper is to test three pelvic macroscopic methods (1-Suchey-Brooks; 2- Lovejoy; 3- Buckberry and Chamberlain) on a documented modern Spanish sample. These methods were selected because they are popular among Spanish anthropologists and because they never have been tested in a Spanish sample. The study sample consists of 80 individuals (55 $\delta$ and 25 \%) of known sex and age from the Valladolid collection. Results indicate that in all three methods, levels of bias and inaccuracy increase with age. The Lovejoy method performs poorly (27\%) compared with Suchey-Brooks (71\%) and Buckberry and Chamberlain (86\%). However, the levels of correlation between phases and chronological ages are low and comparable in the three methods $(<0.395)$. The apparent accuracy of the Suchey-Brooks and Buckberry and Chamberlain methods is largely based on the broad width of the methods' estimated intervals. This study suggests that before systematic application of these three methodologies in Spanish populations, further statistical modeling and research into the co-variance of chronological age with morphological change is necessary. Future methods should be developed specific to various world populations, and should allow for both precision and flexibility in age estimation. 


\section{INTRODUCTION}

Estimating the age-at-death of adult skeletal remains is one of the most important - and most difficult - aspects of forensic anthropological analysis. The methods for estimating age in adult skeletal individuals are based on morphological and degenerative changes in bones and teeth throughout life. The rate and degree of change are determined by a complex set of interactions among genes, culture, and environment that contribute to each individual life history [1-3]. The key to the successful application of a particular method is an understanding of whether the method is accurate (correct), precise (refined), and repeatable from an intra- and interobserver standpoint when applied to unknown individuals outside of the original reference sample [e.g. 4-8]. However, the reference samples on which many of the original methods were based are among very few known age-at-death collections of sufficient sample size for testing purposes [9-11]. Documented reference samples are even rarer outside of the United States. Additionally, variation in the aging process begins to increase during the third decade of life between individuals and within a single skeleton, and continues to increase throughout life [12]. The error in age estimation can be quantified only when a method is tested on a contextualized osteological collection or on individuals of known chronological age. A contextualized collection includes known demographic data (sex, age, year of birth, geographical area) as well as the socioeconomic and temporal context in which the individuals lived [13].

Two of the most common locations for the examination of the morphological changes related to the aging process are the pubic symphysis and auricular surface of the ilium. Todd [14] developed the first formal standards for determining skeletal ageat-death from pubic symphyseal morphology for white males in the Hamann-Todd collection. Todd later expanded the method to include white females and black males and females [15-17]. More recently, Katz and Suchey [18], refined the Todd phase 
method using a sample of modern autopsied remains from the Los Angeles County Coroner's Office. They concluded that sex- and population-based differences have a considerable impact on the reliability of the method. However, for American samples, the resulting Suchey-Brooks method [19] is commonly considered to be the best age estimation method, and is widely used in forensic anthropology and bio-archaeological contexts [10]. The Suchey-Brooks reference sample is large and includes a number of modern North American ethnic groups. However, despite its popularity, pubic symphyseal age assessment has not performed well in validation studies outside the U.S, including those based on modern French autopsied individuals [20], Canadian pioneers [4], and modern Portuguese and Italian individuals from cemetery collections $[10,21]$. These studies have demonstrated biased age estimates and difficulty in determining the age of individuals over 35 years. Furthermore, Sinha and Gupta [22] observed differences in the timing of age-progressive pubic changes U.S. and Indian samples; Hoppa [23] observed similar differences between U.S. and English samples.

The original standards for estimating skeletal age-at-death from the auricular surface of the ilium were developed by Lovejoy et al. [24] using archaeological samples (Libben collection), American cadaver collections from the early twentieth century (Hamann-Todd collection), and forensic cases from the Cuyahoga County Coroner's Office. In burial contexts, the auricular surface often preserves better than the pubic symphysis and the morphological changes continue well into the sixth decade of life. However, the Lovejoy method is more difficult to apply than the Suchey-Brooks method, and validation studies have shown that the auricular surface method suffers from repeatability problems [e.g., 25,26]. Saunders et al. [4] used a small, documented population from Belleville, Ontario and reported overall agreement with Lovejoy et al. [24], but the reliability of the method decreased after age 45. On Portuguese and Italian individuals, Santos [21] and Hens and colleagues [10] found similar results. Using the Grant collection at the University of Toronto, Bedford and colleagues [27] found that the 
auricular surface method overestimated the ages of younger individuals and underestimated the ages of individuals over 50 by as much as $5-10$ years.

Results for a Thai sample were inaccurate and imprecise enough for Schmitt [2] to conclude that both the Suchey-Brooks and Lovejoy methods should be avoided on Asian samples.

Using 180 individuals of known age-at-death from the Spitalfields collection (London), Buckberry and Chamberlain [28] revised the Lovejoy method and proposed a new methodology. The revised method is based on the characteristics described by Lovejoy and colleagues, but recognizes that the age-related features in the auricular surface change independently of one another. In this method, each auricular surface feature is analyzed and scored independently and then combined into a composite score related to a broad age range. This method is the most recent of the three, and although some authors have proposed modifications [26,29]; it has rarely been evaluated using documented osteological collections [30].

Information about the applicability of aging methods to samples from different populations and knowledge of population variation in aging processes are vital to successful adult age estimation. However, few studies have evaluated population differences in the accuracy of aging methods. With the exception of the Buckberry and Chamberlain method that was developed in London, these pubic symphysis and auricular surface methodologies have been developed and tested on modern skeletal samples (samples from later $19^{\text {th }}$ century to present) derived from North American populations $[4,25,27,31,32]$. As we have seen before, only a few studies are based on samples outside of the U.S, including India [22], Thailand [2], Great Britain [23], France [20], Italy [10] and Portugal [21]. To supplement this literature, the current study evaluates three methods for adult age estimation using the pubic symphysis [19] and the iliac auricular surface [24,28] on a modern documented Spanish sample. Specifically, our purpose is to analyze the accuracy and applicability of the methods to contemporary Spaniards, and inform our understanding of skeletal aging processes in 
Spanish populations. These three methods (Suchey-Brooks, Lovejoy, and Buckberry and Chamberlain) were selected because of their popularity in forensic and bioarchaeological contexts [10] and because they never have been tested in a Spanish sample. The Lovejoy and Suchey-Brooks methods are among the most popular methods utilized by Spanish anthropologists. In Spanish anthropological manuals, both are highly recommended [33,34], but they remain largely untested on Spanish population. Likewise, the more recent Buckberry and Chanberlain method has been rarely evaluated in a documented collection; our goal was to test its performance in relation to the Lovejoy method in the Spanish context.

\section{MATERIAL AND METHODS}

The skeletal sample

Data were collected from the modern documented skeletal collection housed in the Museo Anatómico de la Universidad de Valladolid (Valladolid, Spain), which comprises 217 individuals interred in the cemeteries of Palencia and Valladolid. This $20^{\text {th }}$ century collection includes 124 males and 93 females ranging from 20 to 101 years of age-at-death. Demographic information, including age-at-death, was derived from obituary records [35]. Like most modern reference collections, the Valladolid sample is comprised of primarily older individuals with approximately twice as many males as females [13]. Individuals displaying innominate pathologies were excluded from the study, while individuals with non-inflammatory osteoarthritis or diffuse idiopathic skeletal hyperostosis were included as these conditions are commonly related to age. A total of 80 individuals (55 males and 25 females) from 23 to 101 years old were selected for the analysis. As differences between right and left pubic symphyses [10] and auricular surfaces $[28,26]$ are negligible, the left side was scored in nearly every case, although the right side was used if the left was damaged, pathologic or unavailable. Table 1 provides descriptive statistics for the individuals of the sample who 
were selected for analysis by sex. Figure 1 depicts the chronological distribution of females and males examined during the course of analysis. T-tests show that the differences in mean ages-at-death for males (55.58 yrs.) and females (63.84 yrs.) bordered on statistical significance $(t=1.80, p=0.08)$. The female sub-sample is slightly older and more evenly distributed than the male sub-sample.

While the sample is biased toward older adults, this accurately reflects the composition of contemporary documented samples in Spain [13] and is an opportunity to test the accuracy and reliability of the methods on a population subset that desperately requires additional study.

During the laboratory component of the study, the innominates were isolated from the rest of the skeleton and the observations were completed without knowledge of chronological age, avoiding any subjective or objective information that could bias the observations.

\section{Statistical methods}

The success in the performance of an aging method can be defined as the proximity of an age estimate to an individual's actual chronological age [36]. We analyzed the success in the performance of the Suchey-Brooks, Lovejoy, and Buckberry and Chamberlain aging methods in two ways: 1) by scoring the accuracy; that is, whether or not the chronological age of each individual was included in the age ranges provided for each method; and 2) by calculating bias and absolute error for each method. Both bias and absolute error are good indicators of at method's inaccuracy [26]. Bias is the statistical measure that identifies the direction of the committed error in a method's misclassification $[2,5,10,25,21]$ - whether the estimated age is over- or underestimated. If the estimated age is older than the chronological age then the bias is positive. If the estimated age is younger than the chronological age then the bias is negative. Bias was calculated as the average difference between 
estimated age and chronological age using each method ( $\Sigma$ (estimated age chronological age)/n).

Absolute error is the statistical measure that evaluates the degree of the committed error in a method's misclassification [2,5,10,25,21]. Absolute error was calculated as the average absolute difference between estimated age and chronological age using each method $(\Sigma$ |estimated age - chronological age $/ / n)$. In essence, absolute error represents absolute difference; it does not take into account the sign (positive or negative) of the difference between estimated age and chronological age.

Age estimation methods do not produce specific point estimates of estimated age, but rather, estimated intervals of age (e.g., 45-55). Thus, the extreme of the age range nearest to the chronological age was used to calculate the bias and the absolute error of the estimation. For example, if an individual with a chronological age of 65 years has been estimated at between 45-55 years of age, then the bias observed in this specific individual is -5 years $(55-65=-5)$ and the absolute error is 5 years $(\mid 55-$ $65 \mid=5$ ). Contrarily, if the chronological age of the individual was 40 years and the estimated age was $45-55$ years; then the bias would be +5 years $(45-40=+5)$ and the absolute error 5 years $(|45-40|=5)$

Differences in the number of correctly and incorrectly classified individuals (accuracy) between methods and sexes were evaluated with Chi-square tests of independence. Differences in the value of bias and absolute error between methods were evaluated with ANOVA tests.

In order to evaluate the applicability of the three analysed methods to the Spanish population, two types of analyses were conducted:

1) the relationship between trait expressions (or phases) of a particular method and known chronological age was evaluated numerically by Spearman's correlation coefficient. The Spearman's correlation coefficient or Spearman's rho is a non parametric test of statistical dependence between two variables. It is used when one or 
both of the variables consist of ranks, like the phases of the adult aging methods. Spearman's correlation coefficient assesses how well the relationship between two variables can be described using a monotonic function. If there are no repeated data values, a perfect Spearman correlation of +1 or -1 occurs when each of the variables is a perfect monotone function of the other.

2) the extent to which chronological age is capable of predicting membership in the phases for all three aging methods was analyzed via Unrestricted cumulative probit (ordinal) regression analyses [37]. Commonly referred to as Transition Analysis in the age estimation literature [38], probit regression analyses yield intercepts and slopes for each phase of a respective aging method that can be converted to means and standard deviations with the maximum likelihood function provided by the probit regression. This estimate represents the maximum likelihood at which an individual is most likely to transition from one phase to the next. Like the original Transition Analysis [38], the current analyses assume that the developmental trajectory for the phases of each aging method can be broken down into an invariant sequence of "n" distinct, nonoverlapping stages. Furthermore, it is assumed that the morphological change is strictly unidirectional with respect to those phases of each method. The assumptions of Transition Analysis and related approaches fit well with the phase systems used to score age-related changes in adults. For this reason, approaches similar to Transition Analysis are being used in the anthropological literature to study senescent changes in bone [39]. For a more complete discussion of Transition Analysis, see Boldsen et al. [38] and Steadman et al. [40]. All statistics were calculated with SPSS 18.0

\section{RESULTS}

For clarity, the results of the error analyses will be presented first, followed by the results of the test on the applicability of the methods to Spanish skeletal samples. 
1) Accuracy of the Suchey-Brooks, Lovejoy and Buckberry and Chamberlain methods

\section{Accuracy}

For the purposes of this analysis, accuracy is defined as whether or not the chronological age of each individual was included in the age ranges provided for each method. The initial comparison of the accuracy of the three aging methodologies show that the Lovejoy aging method performed poorly ( 20 of a total of 73 individuals were accurately estimated) when compared to both the Buckberry and Chamberlain (61 of a total of 71 individuals) and Suchey-Brooks (35 of a total of 49 individuals) methods (Table 2). The null hypothesis for the independence of the two variables (i.e., accuracy and aging method) was rejected with a chi-square value of $54.8(\mathrm{p}<0.001, d f=2)$. A second chi-square test comparing the performance of the Buckberry and Chamberlain with $86 \%$ accuracy (61 accurate of a total of 71 specimens) and Suchey-Brooks methods with $71 \%$ accuracy (35 accurate of a total of 49 specimens) revealed there was not a significant difference between their accuracies with a test statistic of $3.8(p>$ 0.05 , $d f=1)$. Therefore, taking into account these results, the Buckberry and Chamberlain and Suchey-Brooks methodologies have comparable accuracies for the current Spanish sample.

Table 2 also shows the accuracy of each method when segregated by sex. The performance of the Buckberry and Chamberlain method varied significantly by sex with low female and moderately high male accuracy $\left(x^{2}=8.29, p=0.004\right.$, $\left.d f=1\right)$, while the Lovejoy et al. $\left(x^{2}=1.27, p=0.26, d f=1\right)$ and Suchey-Brooks $\left(x^{2}=0.42, p=0.84\right.$, $d f=$ 1) methods were comparable amongst males and females.

Figure 2 shows the distribution of the accurate and inaccurate age estimates for each individual in relation to the chronological age of the individual and the phases attributed to the individual in each method. Phase 1 in the three methodologies and phase 2 and 3 in Buckberry and Chamberlain method are not shown in figure 2 because they have not been attributed to any individual. 
As shown in figure 2, inaccurate estimates for the Buckberry and Chamberlain method were restricted to phase 7 (53-92 years), while the majority of inaccurate Suchey-Brooks estimates occurred during phases 5 (28-83 years) and 6 (42-87 years). By contrast, accurate estimates were almost entirely restricted to the final two phases of the Lovejoy method, phase 7 (50-60 years) and phase 8 (60+years). Figure 2 also depicts the age-progressive pattern of the phases in all three methods. As anticipated, the variance increases in all three methods in the higher phases.

Bias and Absolute Error- Table 3 provides the descriptive statistics for bias associated with the three aging methods. The Buckberry and Chamberlain method performed comparatively well with regards to bias. Of the ten individuals with inaccurate age estimates, four individuals' ages were underestimated and six were overestimated. By comparison, the ages of 43 of the 73 individuals analyzed using the Lovejoy method were underestimated. The ages of 10 individuals were overestimated. These results demonstrate that the 5-year intervals currently employed by the Lovejoy method are too narrow and hence ineffective for the current Spanish sample. The Suchey-Brooks method overestimated the ages of three individuals and underestimated the ages of 11 individuals.

Table 4 provides the descriptive statistics for the absolute error associated with the three aging methodologies. The absolute error was significantly different among the three methods $(F=18.88$, df $=2,190, p=0.000)$. Like the measure of bias, the absolute error for the inaccurate cases was greatest for the Lovejoy method.

\section{2.) The applicability of the methods to Spanish skeletal samples}

Table 5 presents the non-parametric Spearman's correlations for the phases and chronological ages in the Valladolid sample. The levels of correlation for the three aging methods are comparable, suggesting they all capture roughly the same information about the aging process in Spanish populations. With their broad 
confidence intervals the Buckberry and Chamberlain and Suchey-Brooks methods outperformed Lovejoy in terms of accuracy (see above), however, the levels of association with the aging process are indistinguishable. These findings indicate that broadening of the age intervals associated with the Lovejoy method would result in virtually identical measures of accuracy, bias, and absolute error as the Buckberry and Chamberlain and Suchey-Brooks aging methods.

An important consideration is the extent to which chronological age is capable of predicting membership in the phases for all three aging methods. With continued calls for population-specific aging methods and legal challenges to the reliability and replicability of scientific methodologies, quantifying the performance of aging methods has never been more important. Using a probit-based model of ordinal regression, the co-variate of known chronological age was regressed against age phase membership (Transition Analysis). The results of the Transition Analysis for the three methodologies are depicted in figure 3 . In it, each line is the probability density of one specific age phase of one specific age method throughout the different ages of the individual life. It describes the relative likelihood for this phase to occur at a given age. For example, in the Buckberry and Chamberlain method, the maximum likelihood to have phase 6 is around 60 years of age and the maximum likelihood to have phase 7 is around 100 years (Figure 3). In this way, we can know the age at which it is most probable to be classified in a specific phase of one specific method, thus indicating the age of transition between the different phases in a specific method. The ideal aging method would have the probability density of each phase well delimited and would exhibit minimal overlap between phases. However, this is not possible in adult age estimation methods; due to the great variability in the aging process, some (more or less great) overlap between phases is usually found. Therefore, the smaller the overlap between the phases of a specific method, the more statistically significant the fitted model is. Significance in the fitted model indicates the applicability of the method in terms of 
accuracy and precision. Therefore, the more significant the model, the more applicable the method is.

The principal characteristic shown in figure 3 is the overlap between the different phases in each method. The data were consistent with the estimates of the fitted model for the three methods; however due to the overlap of the phases there is low strength in the logistic regression model in the three methodologies $\left(R_{\text {Buckberry- }}^{2}\right.$

Chamberlain= $\left.0.21 ; R_{\text {Lovejoy }}^{2} 0.20 ; R_{\text {Suchey-Brooks }}^{2}=0.14\right)$, the lowest being the one obtained in Suchey-Brooks method. As depicted in figure 3, the parameters estimated and regression coefficients were significant only for some phases of each method. For Buckberry and Chamberlain method only phases 4, 5 and 6 were significant, indicating that this method is applicable to Spanish populations, but that further statistical modelling and research into the co-variance of chronological age with morphological change would be necessary.

In the Lovejoy method only phases 4, 5, 6 and 7 were significant. Provided that the age intervals associated with the morphological changes were adjusted, the Lovejoy method is potentially applicable to Spanish populations. Additional research on Spanish reference samples is recommended prior to the method's systematic application in forensic and archaeological contexts.

In the Suchey-Brooks method only phase 5 was significant. The Suchey-Brooks method is the weakest of the three methods applied to this sample, though the subsample size was substantially smaller ( $n=49$ vs. $n=73$ ). Spanish reference samples with additional younger individuals of less than 50 years of age would be necessary to test all three methods in an appropriate manner.

\section{DISCUSSION}

This study has evaluated the accuracy and bias of three methods for adult age estimation based on the pubic symphysis (Suchey-Brooks method) and auricular surface (Lovejoy and Buckberry and Chamberlain methods) from a Spanish skeletal 
collection. These methods were selected because they are the most popular among Spanish anthropologists [33] and because they never have been tested in a Spanish sample. Unfortunately, and in spite of the methods' popularity in Spain, the present study has shown that the application of the three methods to a Spanish sample may be problematic. According to the results of this study, the methods differ significantly in their performances: the Lovejoy method estimates age poorly ( $27 \%$ accuracy), while both the Suchey-Brooks and Buckberry and Chamberlain methods estimate age with higher accuracy $(71 \%$ and $86 \%$, respectively). The accuracy of the latter two methods differs only by $15 \%$. However, while the Suchey-Brooks and Buckberry and Chamberlain methods outperform the Lovejoy method with regards to accuracy, it is important to consider the width of the error intervals associated with the phases for these methods. The Lovejoy method was developed prior to the recommendation of statistically sound $95 \%$ confidence intervals. Based on its performance here and in other studies, it is clear that the 5-year phase intervals used by the Lovejoy method were overly optimistic about the quality of skeletal data and the consistent rate of agerelated change. In contrast, the $95 \%$ confidence interval phases for the Buckberry and Chamberlain and Suchey-Brooks methods are very broad and reflect the general quality of information on the aging process contained in the human skeleton. For example, Stages IV (29-81 yrs) and V (29-88 yrs) in the Buckberry and Chamberlain method have interval widths of 52 and 59 years, respectively, that cover nearly the entire adult lifespan of humans.

The Spanish sample shows higher levels of accuracy than the Portuguese sample studied by Santos [21] when the Lovejoy and Suchey-Brooks methods were applied. However, the levels of bias and absolute error in the Portuguese sample are lower. The Spanish sample shows similar absolute error to the U.S. sample reported by Murray and Murray [25] for the Lovejoy technique. The Spanish sample demonstrates lower levels of bias and absolute error than the Thai sample used by Schmitt [2], the Canadian sample of Saunders et al. [4] and the Italian sample of Hens et al. [10] for the 
Lovejoy and Suchey-Brooks methods. It also shows lower bias and absolute error than the U.S. sample of Mulhern and Jones [30] for the Buckberry and Chamberlain method. On the other hand, correlation coefficients between age phases and chronological age for the present study are lower than those reported for the Spitalfields sample by Buckberry and Chamberlain [28]. They reported coefficients of Spearman's correlation around 0.62 whereas the present study reports 0.37 and are similar to those obtained by the Lovejoy and Suchey-Brooks methods. All of these results indicate that the age/indicator relationship is quite variable among populations and support the observations of previous authors $[5,10,21,25,26]$. Furthermore, as these previous authors indicated $[5,10,26]$ this variability increases with age.

One of the main problems of the adult aging methods is the estimation of age in the elderly. This is due to the great variability expressed by the age markers during the aging process, specifically in older ages. Age-related morphological changes in the skeleton occur as an individual undergoes growth, development, and maturation. The appearance of the age markers in an individual skeleton will vary depending on an individual's life history. Influencing factors include health status, diet, living environment, cultural practices, and the presence of disease and trauma experienced during life $[41,42]$. In sub-adult individuals this change occurs more predictably but once skeletal development has ended, maturation of the skeleton occurs with less of an age-specific chronology [43-45]. There are no set rates for the maintenance of the adult skeleton $[19,46]$ and for this reason, the observed variability in the age markers increases and the accuracy of the aging methods decreases with age.

With the intention of reducing the effects of the age markers variability in the aging methods of Lovejoy and Buckberry and Chamberlain, Osborne et al. [29] and Falys et al. [26] reduced the number of the phases and stages of these methods. Obsborne collapsed Lovejoy's eight phases into a six phase system. Falys also reduced Buckberry and Chamberlain's seven stages into three. In this way both authors achieved an increase in the accuracy of both methods, specifically in older 
ages. However, these two new proposals have very broad intervals and reflect the general poor quality of information on the aging process contained in the human skeleton. For example the age range of phase III proposed by Falys and colleagues is from 21 to 91 ; and the age ranges of phases 5 and 6 proposed by Osborne are 24-82 and 29-89, respectively. Thus, these new proposals, together with Suchey-Brooks and Buckberry and Chamberlain, are based on broad intervals with ranges that include most adult ages, therefore making it difficult for the chronological age to not be included in the estimated interval. These methods sacrifice precision for accuracy. However both precision and accuracy are very important for individual identification, and forensic anthropologists should be committed to improving both. Establishment of the identity of an individual is of the utmost medico-legal significance, both in living and dead, especially in cases of murder or mass disasters, where the bodies are grossly mutilated or in advanced stages of decomposition. For identification, apart from sex (which excludes almost half of the population), age is one of the most important criteria for excluding large portions of the population [47].

Accuracy and reliability of older adult age intervals among the Spanish are particularly relevant in Spanish bioarchaeology and forensic anthropology, as such population variation data are particularly important to ongoing human rights investigations of mass graves from the Spanish Civil War era. Since 2000, archaeologists have worked to recover historic memory of the Spanish Civil War by exhuming the remains of victims of extrajudicial executions (cf [48-50]). Physical anthropologists developing biological profiles of the victims for identification purposes have had to rely on the available skeletal aging standards, most of which were developed on U.S. reference samples. The magnitude of error involved in applying these methods to Spanish individuals who were likely born around the beginning of the 20th century is unknown, and great errors have been observed when U.S. reference standards have been applied to Spanish samples. For example, the method for calculating stature based on U.S. reference samples fails in the estimation of living 
height in Catalonia. In Catalonia, the formulae proposed by Pearson [51] at the end of 19th century based on a French sample perform better, because of the biological population history of French and Catalan populations [13,33].

It must be emphasized that precision in forensic anthropology is important for individual identification and broad intervals of estimated age are not very useful. Therefore, the results of this study suggest that future methods of skeletal age estimation should allow for precision and flexibility in both: 1) applying different reference collections to different target populations and 2) estimating the age of an individual taking into account the variability observed in the feature. This flexibility can be found in methods based on Bayesian prediction. The success of this mathematical procedure, which generates accurate and less biased age estimates, has been demonstrated by several authors [3, 52-55].

\section{CONCLUSIONS}

This study has evaluated three methods for adult age estimation based on the pubis symphysis (Suchey-Brooks) and the auricular surface (Lovejoy and Buckberry and Chamberlain) in a Spanish sample. Results indicated that the Lovejoy method estimates age poorly (27\%) with clear differences in accuracy from Buckberry and Chamberlain (86\%), and Suchey-Brooks (71\%). However the accuracy of the Buckberry and Chamberlain and Suchey-Brooks methods are based on the width of the estimated intervals of age, which include most of adulthood, making it difficult for the chronological age to fall out of the estimated interval. This study suggests that future methods of skeletal age estimation should allow for precision and flexibility in applying different reference collections to different target populations and estimating age from the observed features in the age markers. This precision and flexibility is observed in methods based on Bayesian prediction. Additional research on Spanish 
reference samples is recommended prior to applying systematically in forensic and archaeological contexts the three methods evaluated in the present study.

\section{ACKNOWLEDGEMENT}

This work was funded by the Ministerio de Ciencia e Innovación research project no. CGL2006-02170/BTE and the Generalitat de Catalunya research project 2009SGR884GRQ-Grup d'Estudis d'Evolució d'Homínids i d'Altres Primats.

We are grateful to Professor Francisco Pastor from the Department of Anatomy of the Valladolid University (Valladolid, Spain) for providing access to the Human Skeletal collection of Valladolid.

\section{REFERENCES}

1. Kemkes-Grottenthaler A (2002) Aging through the ages: historical perspectives on age indicator methods. In: Hoppa RD, Vaupel JW (eds). Paleodemography. Age distributions from skeletal samples. Cambridge University Press, Cambridge, pp 49-72.

2. Schmitt A (2004) Age-at-death assessment using the os pubis and the auricular surface of the ilium: a test on an identified Asian sample. Int J Osteoarchaeol 14:1-16.

3. Rissech C, Estabrook GF, Cunha E,Malgosa A (2007) Estimation of age at death for adult males using the acetabulum, applied to four Western European Populations. J Forensic Scien 52:774-779.

4. Saunders SR, Fitzgerald C, Rogerts T, Dudar C, McKillop H (1992) A test of several methods of skeletal age estimation using a documented archaeological sample. Can Soc Forensics Sci J 25:97-118. 
5. Martrille L, Ubelaker DH, Cattaneo C, Seguret F, Tremblay M, Baccino E (2007) Comparison of four skeletal methods for the estimation of age at death on white and black adults. JForensic Scien 52:302-307.

6. Wittwer-Backofen U, Buckberry J, Czarnetzki A, Doppler S, Grupe G, Hotz G, Kemkes A, Spencer-Larsen CL, Prince D, Wahl J, Fabigm A, Weise S (2008) Basics in paleodemography: A comparison of age indicators applied to the early medieval skeletal sample of Lauchheim. Am J Phys Anthropol 137:384-396.

7. Konigsberg LW, Herrmann NP, Wescott DJ, Kimmerle EH (2008) Estimation and evidence in forensic anthropology: Age-at-death. J Forensic Sci 53:451557.

8. Kimmerle EH, Konigsberg LW, Jantz RL, Baraybar JP (2008) Analysis of ageat-death estimation through the use of pubic symphyseal data. J Forensic Sci 53:558-568.

9. Usher BM (2002) Reference samples: the first step in linking biology and age in the human skeleton. In: Hoppa RD, Vaupel JW (eds). Paleodemography: age distributions from skeletal samples. Cambridge University Press, Cambridge, pp 29-47.

10. Hens SM, Rastelli E, Belcastro G (2008) Age estimation from the human os Coxa: a test on a Documented Italian Collection. J Forensic Sci 53:1040-1043.

11. Rissech C (2008) Estimación de la edad biológica de los restos subadultos. In: Gusi-Gener F, Muriel S, Olária C (eds). Nasciturus, infans, puerulus vobis mater terra: la muerte en la infancia. Servei d'Investigacions Arqueològiques i Prehistòriques. Diputació de Castelló, Castelló. pp 72-92.

12. Meindl RS, Russell KF (1998) Recent advances in method and theory in Paleodemography. Ann Rev Anthropol 27:375-99.

13. Rissech C, Steadman DW (2010) The demographic, socio-economic and temporal contextualisation of the Universitat Autònoma de Barcelona Collection of Identified Human Skeletons (UAB Collection). Int J Osteoarchaeol doi: 10.1002/oa.1145. 
14. Todd TW (1920) Age changes in the pubic bone. I. The male white pubis. Am J Phys Anthropol 3:285-334.

15. Todd TW (1921a) Age changes in the pubic bones. II. The pubis of the male Negro-white hybrid. III. The pubis of the white female. IV. The pubis of the female Negro-white hybrid. Am J Phys Anthropol 4: 4-70.

16. Todd TW (1921b) Age changes in the pubic bones. V. Mammalian pubic bone metamorphosis. Am J Phys Anthropol 4: 333-40.

17. Todd TW (1921c) Age changes in the pubic bones. VI. The interpretation of variations in the symphyseal area. Am J Phys Anthropol 4: 407-424.

18. Katz D, Suchey J (1986) Age determination of the male os pubis. Am J Phys Anthropol 69:427-435.

19. Brooks S, Suchey J (1990) Skeletal age determination based on the os pubis: a comparison of the Acsadi-Nemekeri and Suchey-Brooks methods. Hum Evol $5: 227-238$.

20. Baccino E, Ubelaker DH, Hayek LC, Zerilli A (1999) Evaluation of seven methods of estimating age at death for mature human skeletal remains. $J$ Forensic Sci 44:931-936.

21. Santos AL, (1996) How old is this pelvis? A comparison of age at death estimation using the auricular surface of the ilium and os pubis. In: Pwiti G, Soper RA (eds). Aspects of African Archaeology. Proceedings of the $10^{\text {th }}$ congress of the Pan African Association for Prehistory and related studies; 1995 Jun 18-23; Harare. Print Holdings, Zimbabwe, pp 29-36.

22. Sinha A, Gupta V (1995) A study of estimation of age from the pubic symphysis. For Sci Int 75:73-78.

23. Hoppa RD (2000) Population variation in osteological aging criteria: an example from the pubic symphysis. Am J Phys Anthropol 111:185-191. 
24. Lovejoy CO, Meindl RS, Prysbeck TR, Mensforth RP (1985) Chronological metamorphosis of the auricular surface of the ilium: a new method for the determination of adult skeletal age at death. Am J Phys Anthropol 68:15-28.

25. Murray K, Murray T (1991) A test of the auricular surface aging technique. J Forensic Scien 36:1162-1169.

26. Falys CG, Schutkowski H, Weston DA (2006) Auricular surface aging. Worse than expected? A test of revised method on a documented historic skeletal assemblage. Am J Phys Anthropol 130:508-513.

27. Bedford ME, Russel KF, Lovejoy CO, Meindl RS, Simpson SW, StuartMacadam PL (1993) Test of the multifactorial aging method using skeletons with known age-at-death from the Grant collection. Am J Phys Anthropol 91:287-297.

28. Buckberry JL, Chamberlain AT (2002) Age estimation from the auricular surface of the ilium: a revised method. Am J Phys Anthropol 119:231-239.

29. Osborne DL, Simmons TL, Nawrocki SP (2004) Reconsidering the auricular surface as an indicator of age at death. J Forensic Sci 49:1-7.

30. Mulhern DM, Jones EB (2005) Test of revised method of age estimation from the auricular surface of the ilium. Am J Phys Anthropol 126:61-65.

31. Gilbert BM, McKern TW (1973) A method for aging the female os pubis. Am J Phys Anthropol 38:31-38.

32. Klepinger LL, Katz D, Micozzi MS, Carrol L (1992). Evaluation of cast methods for estimating age from os pubis. J Forensic Scien 37:763-770.

33. Márquez-Grant N, Rissech C, López-Costas O, Caro-Dobón L (2010) Spain/España. In: Marquez-Grant $\mathrm{N}$ and Fibiger L (eds). The Routledge Handbook of Archaeological Human Remains and Legislation: an international guide to laws and practice in the excavation, study and treatment of archaeological human remains. Routledge editorial, London, pp. 423-438. 
34. Campillo D, Subirà E (2004) Antropología física para arqueólogos. Editorial Ariel, Barcelona.

35. Pastor JF, Verona JAG, dePaz FJ, Barbosa E (1995) The anatomical museum of Valladolid. Yamaguchi J Vet Med 22:53-60.

36. Hartnett KM (2007) A re-evaluation and revision of pubic symphysis and fourth rib aging techniques. PhD dissertation. Arizona State University.

37. McCullagh P (1980) Regression models for ordinal data. J Royal Statistical Soc B42:109-142.

38. Boldsen JL, Milner GR, Konigsberg LW, Wood JW (2002) Transition analysis: a new method for estimating age from skeletons. In: Hoppa RD, Vaupel JW (eds). Paleodemography. Age distributions from skeletal samples. Cambridge University Press, Cambridge, pp.73-106.

39. Langley-Shirley N, Jantz RL (2010) A Bayesian approach to age estimation in modern Americans from the clavicle. J Forensic Scien 55:571-583.

40. Steadman DW, Adams BJ, Konigsberg LW (2006) Statistical basis for positive identification in forensic anthropology. Am J Phys Anthropol 131:15-26.

41. Mascie-Taylor CGN, Bogin B (eds) (1995) Human variability and plasticity. Cambridge University Press, Cambridge.

42. Bogin B (2001) The growth of humanity. Wiley-Liss, New York.

43. Maples WR (1989) The practical application of age-estimation techniques. In: İşcan MY (ed). Age markers in the human skeleton. CC. Thomas, Springfield IL, pp 319-324.

44. Schwartz JH (1995) Skeleton keys. Oxford University Press, Oxford.

45. Cox M (2000) Aging adults from the skeleton. In: Cox M, Mays S (ed) Human osteology in archaeology and forensic science. Greenwich Medical Media, London, pp 131-142. 
46. İşcan MJ, Loth SR (1989) Estimation of age and determination of sex from the sternal rib. In: Reichs KJ (ed). Forensic osteology. Advances in the identification of human remains.: CC Thomas, Springfield IL, pp 68-89.

47. Modi NJ (1988) Modi's Medical Jurisprudence and Toxicology. N.M. Tripathi Private Ltd, Bombay, pp. 28843.

48. Gassiot E, Oltra J, Sintes E, Steadman DW (2007) Archaeology of the Spanish Civil War: rescue of the memory and historic justice. In: Hamilakis $Y$, Duke $P$ (eds) Archaeology and Capitalism: From Ethics to Politics. Left Coast Press, Walnut Creek CA, pp 235-245.

49. Gassiot E, Steadman DW (2008) The political, social and scientific contexts of archaeological investigations of mass graves in Spain. Archaeologies 4: 429444.

50. Rios L, Martinez B, Garcia-Rubio A, Jiménez J (2008) Death in captivity during the early Franco regime: exhumation of the cemetery of Valdenoceda prison (1938-1943). Complutum 19: 139-160.

51. Pearson K (1899) Mathematical contributions to the Theory of evolution. V. On the reconstruction of the stature of prehistoric races. Philosophical Transactions of the Royal Society 192: 169-244.

52. Lucy D, Aykroyd RG, Pollard AM, Solheim T (1996) A Bayesian Approach to adult human age estimation from dental observations by Johanson's age changes. J Forensic Sci 41:189-94.

53. Schmitt A, Murail P, Cunha E, Rouge D (2002) Variability in the pattern of aging on the human skeleton: evidence from bone indicators and implications on age at death estimation. J Forensic Sci 47:1203-1209.

54. Rissech C, Estabrook GF, Cunha E, Malgosa A, (2006) Using the acetabulum to estimate age at death of adult males. J Forensic Scien 51:213-219. 
55. Storey R (2007) An Elusive Paleodemography? A comparison of two methods for estimating the adult age distribution of deaths at late classic Copan, Honduras. Am J Phys Anthropol 132:40-47. 


\section{TABLE AND FIGURE CAPTIONS}

Table 1 Age-at-death information by sex for the 80 individuals sampled from the Universidad de Valladolid collection.

Table 2 Accuracy obtained when applied the three methodologies of adult age estimation taking into account the entire sample and the sexes separately. Inaccurate means that the chronological age fell outside of the estimated age interval.

Table 3 Descriptive statistics for bias associated with the three aging methods.

Table 4 Statistics for the absolute error associated with the three aging methods.

Table 5 Spearman's correlation among the aging phases for all three methods and chronological age of each individual.

Fig. 1 Age distribution by sex of the 80 individuals sampled from the Universidad de Valladolid collection.

Fig. 2 Distribution of the accurate $\left(^{*}\right)$ and inaccurate $\left(^{\circ}\right)$ estimations of age for each individual in relation to the chronological age of the individual and the phases attributed to him for each method (Buckberry and Chamberlain, Lovejoy, and Suchey-Brooks). Accurate estimation of age is when the chronological age fell inside the estimated age range. Inaccurate estimation of age is when the chronological age fell outside the estimated age range.

Fig. 3 Provability density of each specific age phase in each specific age method (Buckberry and Chamberlain, Lovejoy, and Suchey-Brooks) throughout the different ages of the individual life. 


\section{TABLES}

\begin{tabular}{|l|cccccccc|}
\hline Sex & n & range & minim. & maxim. & mean & Std Error & SD & variance \\
\hline Female chronological age & 25 & 66 & 35 & 101 & 63.84 & 4.21 & 21.06 & 443.39 \\
Male chronological age & 55 & 71 & 23 & 94 & 55.58 & 1.80 & 13.37 & 178.66 \\
\hline
\end{tabular}

TABLE 1

\begin{tabular}{|c|c|c|c|}
\hline & Total & Males & Females \\
\hline \multicolumn{4}{|l|}{ Buckberry and Chamberlain } \\
\hline Inaccurate & $10(14 \%)$ & $3(6 \%)$ & $7(32 \%)$ \\
\hline Accurate & $61(86 \%)$ & $46(94 \%)$ & $15(68 \%)$ \\
\hline Total & 71 & 49 & 22 \\
\hline \multicolumn{4}{|l|}{ Lovejoy } \\
\hline Inaccurate & $53(72.6 \%)$ & $39(77 \%)$ & $14(64 \%)$ \\
\hline Accurate & $20(27.4 \%)$ & $12(23 \%)$ & $8(36 \%)$ \\
\hline Total & 73 & 51 & 22 \\
\hline \multicolumn{4}{|l|}{ Suchey-Brooks } \\
\hline Inaccurate & $14(29 \%)$ & $10(28 \%)$ & $4(31 \%)$ \\
\hline Accurate & $35(71 \%)$ & $26(72 \%)$ & $9(69 \%)$ \\
\hline Total & 49 & 36 & 13 \\
\hline
\end{tabular}

TABLE 2

\begin{tabular}{|l|rrrrr|}
\hline Method & \multicolumn{5}{|c|}{ Bias } \\
\hline & n & minimum & maxim. & mean & SD \\
\hline Buckberry -Chamberlain & 10 & -9 & 13 & 0.20 & 2.58 \\
Lovejoy et al. & 53 & -39 & 20 & -4.77 & 12.20 \\
Suchey-Brooks & 14 & -36 & 20 & -2.45 & 8.21 \\
\hline
\end{tabular}

TABLE 3 


\begin{tabular}{|l|rrrrrr|}
\hline Method & \multicolumn{7}{|c|}{ Absolute Error } \\
\hline & $\mathbf{n}$ & maximum & mean & Std Error & SD & variance \\
\hline Buckberry -Chamberlain & 10 & 13 & 0.79 & 0.29 & 2.46 & 6.06 \\
Lovejoy et al. & 53 & 39 & 8.36 & 1.18 & 10.05 & 100.98 \\
Suchey-Brooks & 14 & 36 & 3.36 & 1.13 & 7.88 & 62.15 \\
\hline
\end{tabular}

TABLE 4

\begin{tabular}{|l|r|rrr|}
\hline & & $\begin{array}{l}\text { Buckberry and } \\
\text { Chamberlain } \\
\text { Phases }\end{array}$ & $\begin{array}{r}\text { Lovejoy } \\
\text { Phases }\end{array}$ & $\begin{array}{r}\text { Suchey- } \\
\text { Brooks } \\
\text { Phases }\end{array}$ \\
\hline Age & Correlation coef. & 0.369 & 0.394 & 0.354 \\
& $\mathrm{p}$ & $0.002^{*}$ & $0.001^{*}$ & $0.013^{*}$ \\
& $\mathrm{n}$ & 71 & 73 & 49 \\
\hline Buckberry and & Correlation coef. & & & \\
Chamberlain Phases & $\mathrm{p}$ & & 0.858 & 0.371 \\
& $\mathrm{n}$ & & $0.000^{*}$ & $0.010^{*}$ \\
& Correlation coef. & & 71 & 47 \\
\hline Lovejoy Phases & $\mathrm{p}$ & & & 0.344 \\
& $\mathrm{n}$ & & & $0.017^{*}$ \\
& & & & 48 \\
\hline
\end{tabular}

TABLE 5 


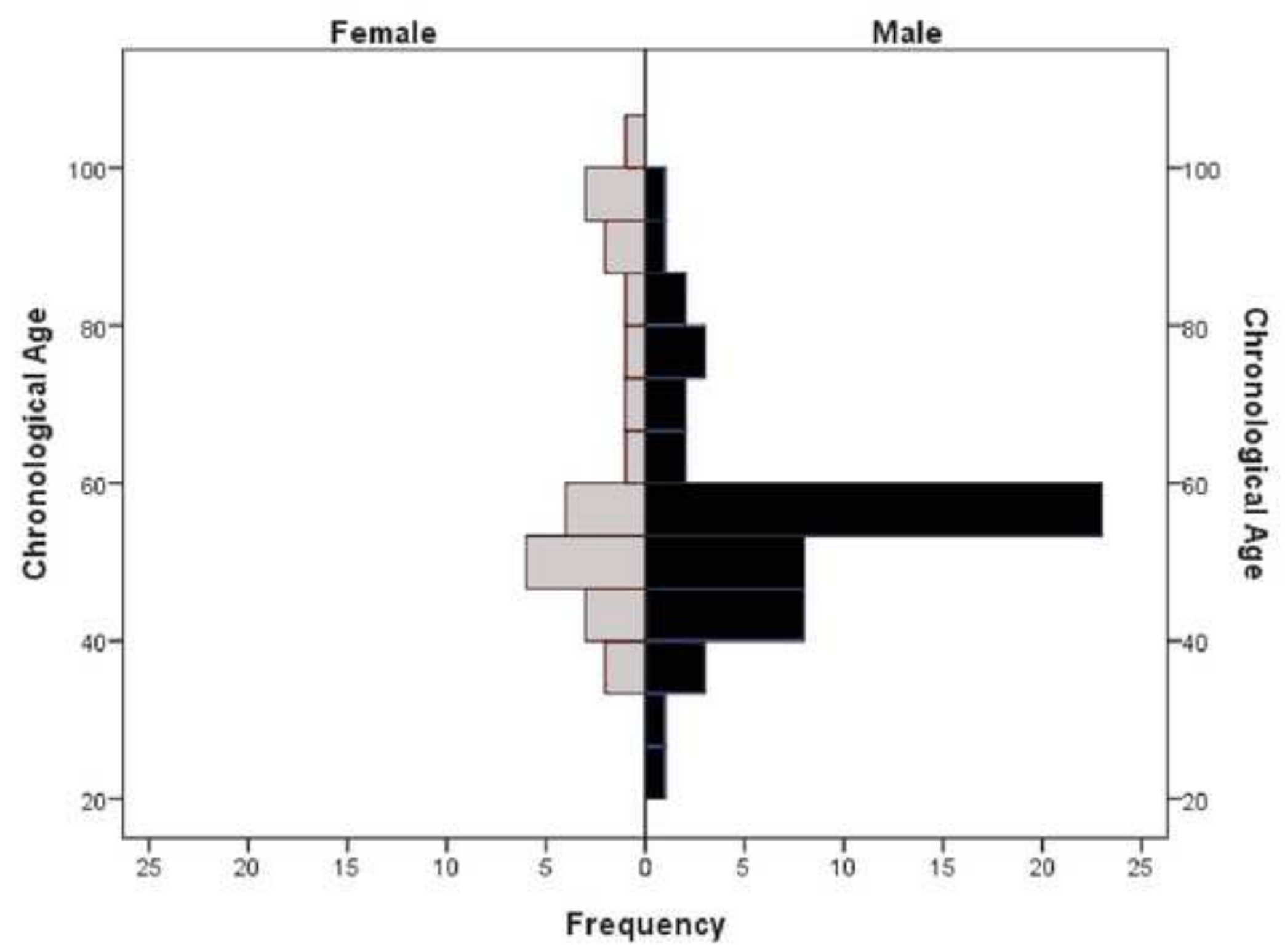


Figure
Click here to download high resolution image
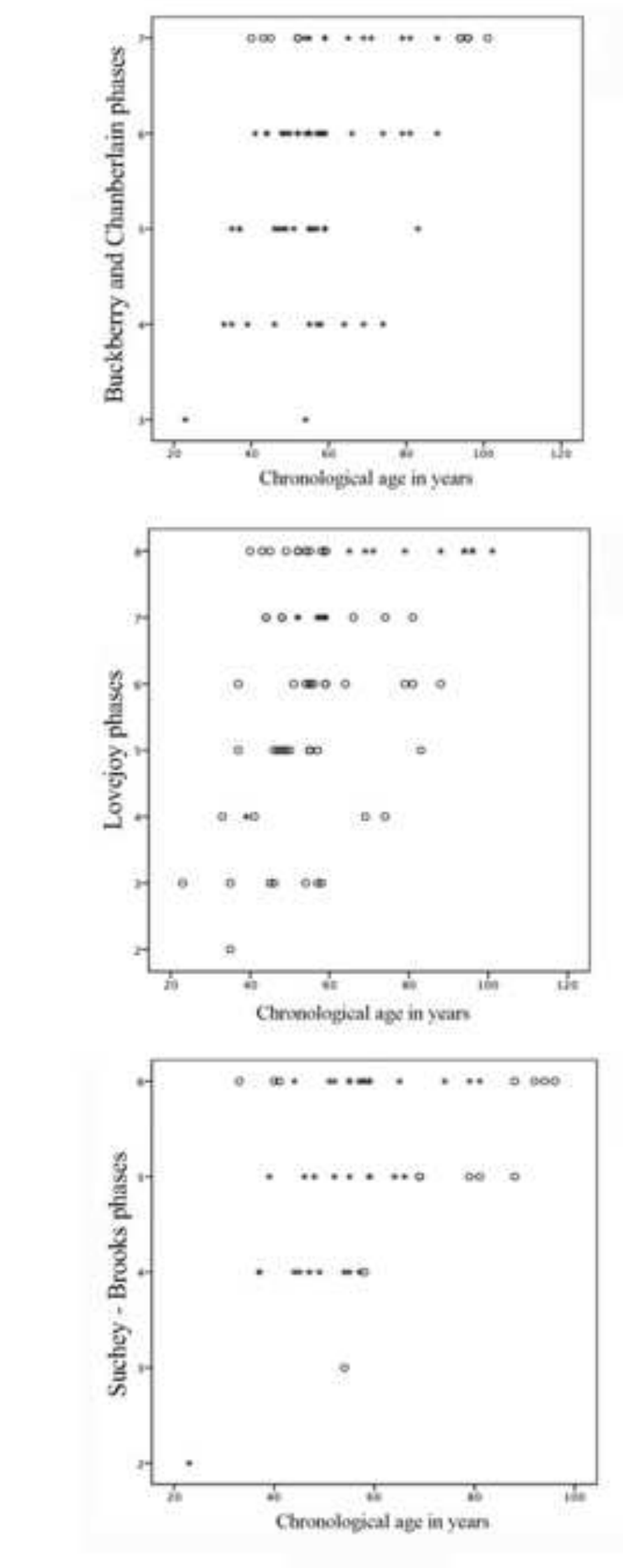

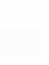

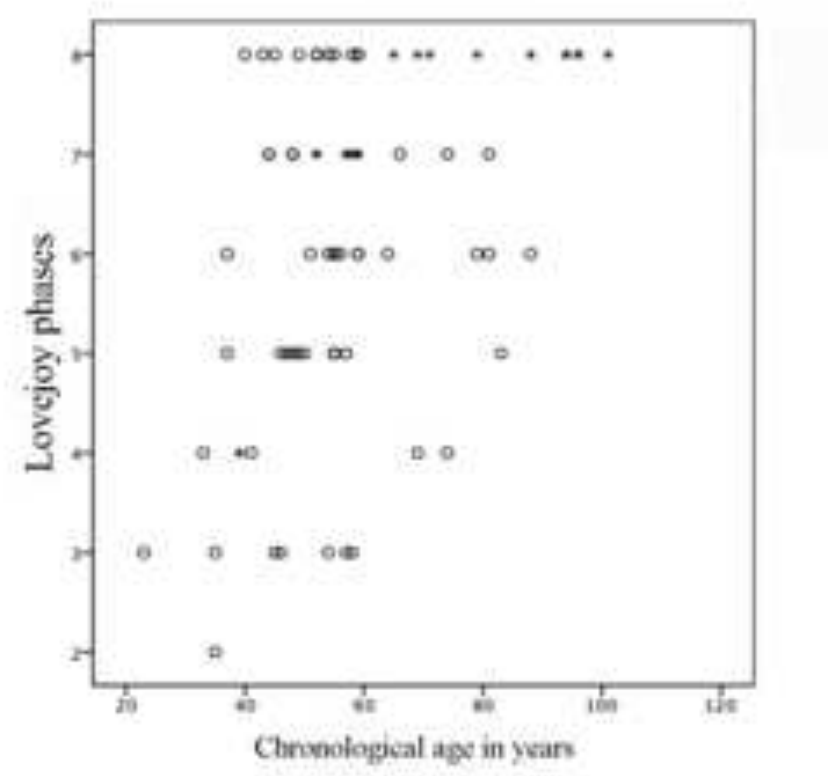

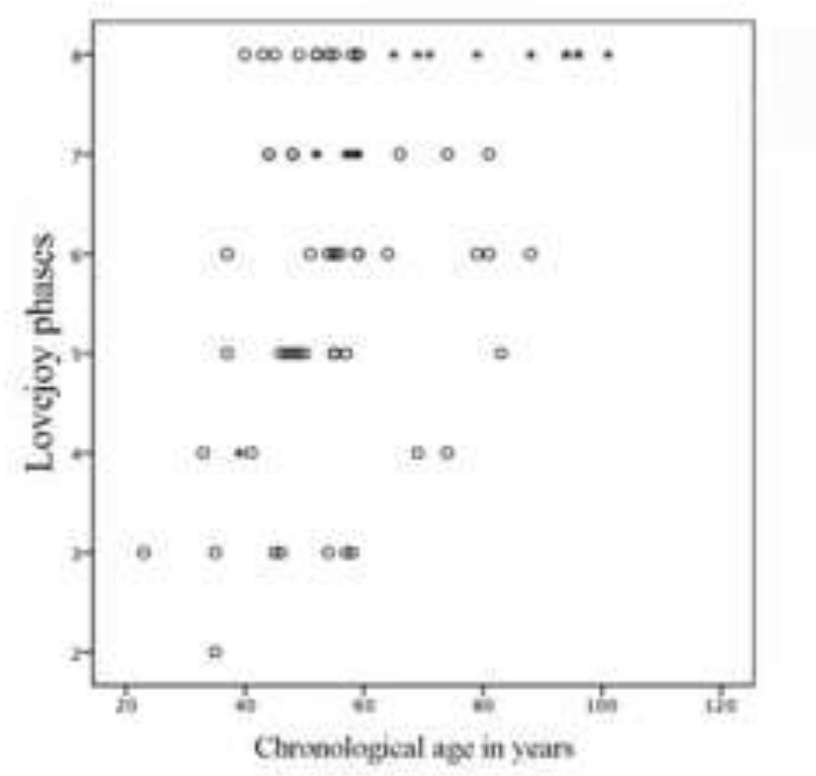

$$
\text { . }
$$
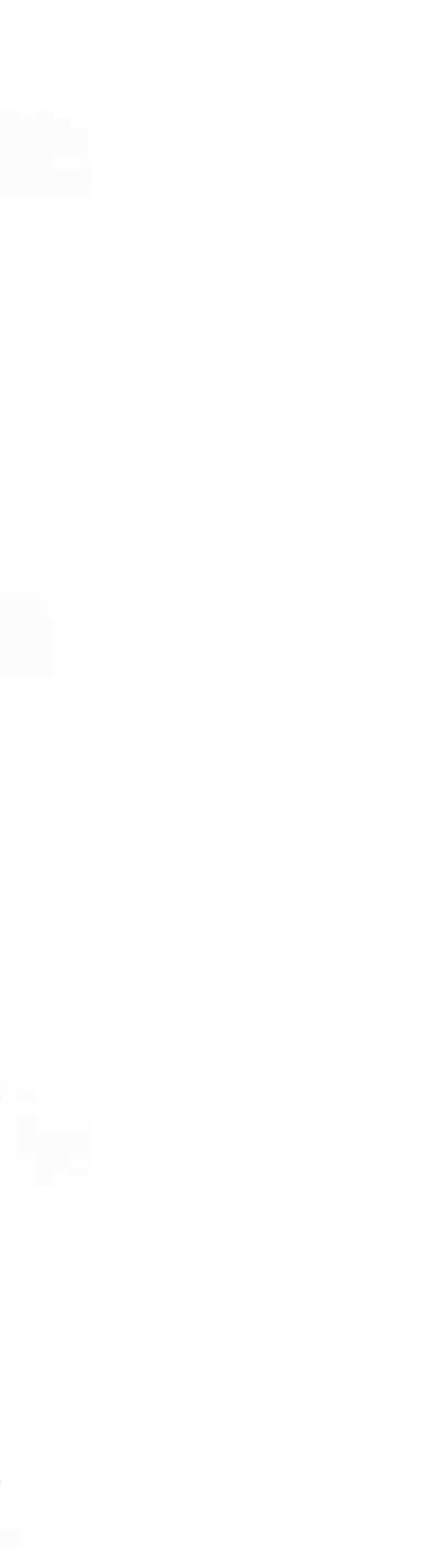
Figure
Click here to download high resolution image

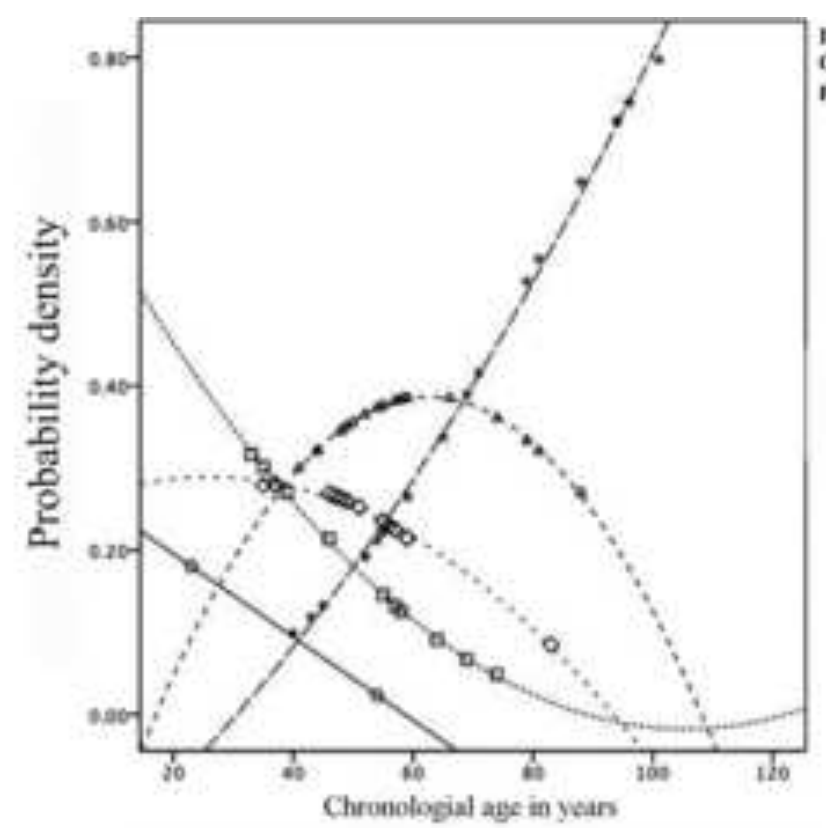

Figure
Click here to download high resolution image

Figure
Click here to download high resolution image

Figure
Click here to download high resolution image

Figure
Click here to download high resolution image

Figure
Click here to download high resolution image
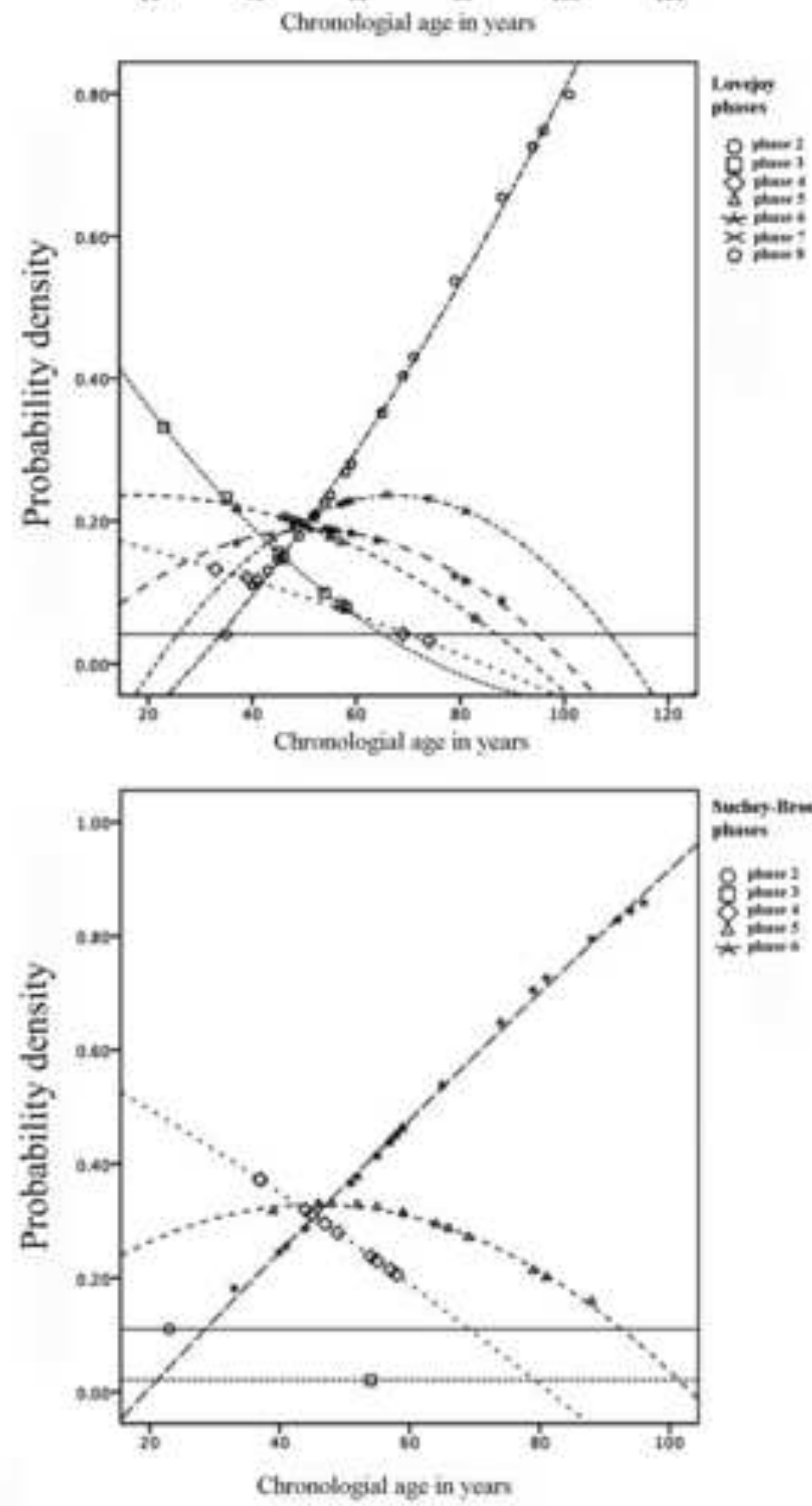

sucher-itriek.
phases

suchey-itriek.
phases

8

8 히:

ㅊ...

trict

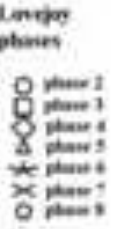

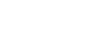

5


Supplementary Material
Click here to download Supplementary Material: Letter.doc

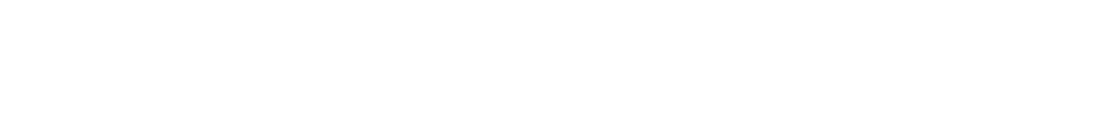

(1)

(1)

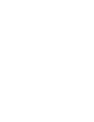

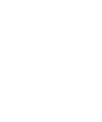

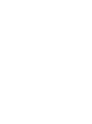

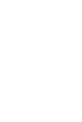

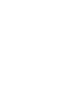

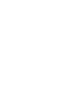

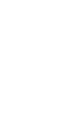

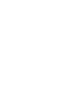

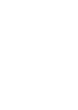

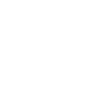

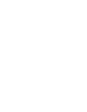

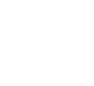

